\title{
Urinary tract infections decreased in Finnish children during the COVID-19 pandemic
}

\author{
Ilari Kuitunen ${ }^{1,2} \cdot$ Miia Artama $^{3,4} \cdot$ Marjut Haapanen $^{1} \cdot$ Marjo Renko $^{1,5,6}$
}

Received: 1 September 2021 / Revised: 1 September 2021 / Accepted: 22 January 2022 / Published online: 31 January 2022

(c) The Author(s) 2022

\begin{abstract}
Social restrictions reduced the rates of respiratory infections in 2020, but studies on the rates of urinary tract infections (UTIs) during lockdown have had conflicting results. This study aimed to report UTI incidence during the first and second waves of COVID-19 pandemic in Finland. We conducted a retrospective register-based cohort study. The whole Finnish pediatric population (children under the age of 15 years, $N=860,000$ ) was included. The yearly and monthly incidences of UTIs per 100,000 children in 2020 were compared to that of three previous years (2017-2019) by incidence rate ratios (IRRs) with 95\% confidence intervals (CIs). A total of 10,757 cystitis and 4873 pyelonephritis cases were included. The yearly incidence of cystitis was $12 \%$ lower (IRR 0.88, CI 0.83-0.94) among children aged 1-6 in 2020 and $11 \%$ (IRR 0.89, CI 0.83-0.95) lower among children aged 7-14 in 2020 compared with previous years. The yearly incidence of pyelonephritis was $16 \%$ lower (IRR 0.84, CI 0.76-0.94) among children aged 1-6. No significant decrease were observed among children aged $<1$ and 7-14.

Conclusion: The incidence of cystitis and pyelonephritis during a period of social restrictions was lower than during 2017-2019, especially in children aged 1-6 years. These results raise the possibility of reducing the occurrence of urinary tract infections in children by improving hygiene measures.
\end{abstract}

\section{What is known:}

- Social restrictions have reduced the rate of common respiratory infections globally.

- Previous studies have presented a decreased or unchanged incidence of urinary tract infections during the COVID-19 pandemic.

What is new:

- During the pandemic, there was a decrease in the incidence of urinary tract infections in Finnish children and the most prominent decrease was in daycare-aged children.

- Improved hygiene measures and social restrictions may have influenced the transmission of uropathogens.

Keywords COVID-19 $\cdot$ Cystitis $\cdot$ Pyelonephritis $\cdot$ Epidemiology $\cdot$ Non-pharmaceutical interventions

\section{Communicated by Nicole Ritz}

Ilari Kuitunen

ilari.kuitunen@uef.fi

1 Institute of Clinical Medicine, Department of Pediatrics, University of Eastern Finland, Kuopio, Finland

2 Department of Pediatrics, Mikkeli Central Hospital, Porrassalmenkatu 35-37, 50100 Mikkeli, Finland

3 Faculty of Social Sciences, Department of Epidemiology, Tampere University, Tampere, Finland

4 Finnish Institute of Health and Welfare, Tampere, Finland

5 Department of Pediatrics, Kuopio University Hospital, Kuopio, Finland

6 PEDEGO Research Unit, University of Oulu, Oulu, Finland

\author{
Abbreviations \\ CI Confidence interval \\ ED Emergency department \\ IRR Incidence rate ratio \\ UTI Urinary tract infection
}

\section{Introduction}

When the World Health Organization (WHO) declared severe acute respiratory corona virus 2 (SARS-CoV-2) a pandemic in March 2020, a majority of countries implemented social restrictions and lockdowns to prevent the spread of COVID-19. In Finland, schools and daycares were closed from March to May 2020. Previous studies 
have shown that these restrictions had a substantial impact on globally decreasing the incidence of common respiratory infections [1-4], acute otitis media cases [1, 5-7], and overall pediatric emergency department visit rates [8-13]. Finnish schools reopened in May 2020 and have remained open since. The reopening of schools had no effect on the spread of respiratory infections in Finland [14]. During the second wave, the strategy to limit the spread of COVID-19 involved minimal restrictions imposed on children. These restrictions were effective in preventing the spreading of respiratory syncytial virus [15] and influenza in fall 2020 [16], but the overall rate of visits to pediatric emergency departments has been normal since summer 2020 [17].

A previous study from the US found that the visit rate due to urinary tract infections (UTI) decreased during the period of lockdown and social restrictions [5]. Also, a recent review found that the rate of non-communicable infectious diseases decreased slightly in March 2020 when the lockdowns began [13]. A few additional reports have shown that the rates of UTI remained stable despite the social restrictions $[7,10]$. Interestingly, a study in Italy found that the rate of UTIs increased in tertiary level units during the lockdown period [12].

The current understanding of pathomechanisms for UTI is the ascending route, the hematogenous route, and the lymphatic route [18]. Especially in young children, anomalies and obstructions causing urinary stasis might increase the likelihood of UTI [19]. In recent years, the pathogenesis and mechanisms of UTI in children have gained more interest, and alternative theories have been studied and presented [20]. It is possible that improved hygiene measures could reduce the transmission of uropathogens from person-to-person or from gut to urinary tract via hands and, therefore, decrease rates of UTI, although UTI is classically defined as a non-communicable disease.

We aimed to evaluate the incidence of urinary tract infections in Finnish children in 2020 during the first and second waves of the COVID-19 pandemic and compare it to that of previous years.

\section{Methods}

Data for this retrospective, nationwide, register-based cohort study were gathered from the national open-access care registers in Finland. The National Care Register is maintained by the Finnish Institute of Health and Welfare, and it includes all visits and hospitalizations in specialized health care [21]. Specialized health care in Finland means public secondary and tertiary level pediatric hospitals, for which all Finnish inhabitants are eligible without insurance. The Primary Health Care register is also maintained by the Finnish Institute of Health and Welfare, and it includes all visits for public primary care, which is publicly funded and open to anyone [22]. Private sector health care is not included in the current study. The whole
Finnish pediatric population of 860,000 children (in 2020) was included in this register-based study.

For this report, we gathered age-stratified monthly numbers of visits due to UTI (cystitis and pyelonephritis) in secondary/tertiary health care for children aged $<1$ year, 1-6 years, and 7-14 years of age from January 2017 to December 2020. UTIs were classified based on the ICD-10 classification. From the primary care register, the yearly visit numbers for children aged 1-6 and 7-14 were gathered for cystitis. Cystitis included diagnosis codes N30.0 and N30.9. Pyelonephritis included diagnosis code N10.

The first wave of COVID-19 lasted from March to May, and the second wave began in September 2020. The restrictions implemented in Finland during 2020 were as follows:

- From January 1 to March 16, there were no restrictions.

- From March 16 to May 16, schools and daycares were closed, gatherings were limited, and a lockdown without curfew was in force.

- From May 16 to September, minimal restrictions were imposed on children, there were no restrictions on outdoor gatherings, and schools and daycares were fully open. Travelling was enabled to low-incidence countries during July and August.

- From September to December, instead of nationwide restrictions, regional stepwise restrictions based on the 14-day cumulative incidence of COVID-19 cases in specific regions were implemented. Schools and daycares remained open. Travel was restricted.

The monthly and yearly incidence with $95 \%$ confidence intervals (CI) per 100,000 children in each age group was calculated by the Poisson exact method, and the incidence rate in 2020 was compared to the mean incidence during 2017-2019 by incidence rate ratios (IRRs) with CI. The agestratified population was gathered for each year from the open-access population reports of Statistics Finland [23]. The number of children living in Finland at the end of each year was used as the nominator in the incidence calculations. This study has been reported according to the EQUATOR guideline of REporting of studies Conducted using Observational Routinely-collected health Data (RECORD).

Due to the retrospective register-based design, ethical committee evaluation was not required or obtained.

\section{Results}

\section{Cystitis}

A total of 10,757 cystitis cases were included and, of these, $2389(22.2 \%)$ were treated in 2020 . The incidence in children aged 1-6 years was 394 per 100,000 in 2020 and 433 per 
100,000 in 2017-2019 (IRR 0.88, CI 0.83-0.94; Table 1). The corresponding incidence in children aged 7-14 was 229 in 2020 and 250 in 2017-2019 (IRR 0.89, CI 0.83-0.95: Table 1). The IRR in children aged 1-14 for diagnose in primary care was 0.83 (CI 0.78-0.88) and in specialized care 0.94 (0.88-1.00: Table 1). Yearly numbers and incidences of cystitis are presented in Supplementary Table 1. During the lockdown in March 2020, the incidence dropped below the reference level in both age groups and returned to near normal levels during the summer (Fig. 1). A second drop was seen among children aged 1-6 in November 2020 (IRR 0.63, CI 0.42-0.95: Fig. 1A).

\section{Pyelonephritis}

A total of 4873 pyelonephritis cases were included and, of these, $1094(22.5 \%)$ were treated in 2020 . The overall incidence for pyelonephritis was 127 per 100,000 children in 2020 and 143 per 100,000 children aged 0-14 in 2017-2019 (IRR 0.89, CI 0.83-0.95: Table 2). Yearly numbers and incidences of pyelonephritis are presented in Supplementary Table 2. The decrease was mostly seen among children aged 1-6 years, in whom the incidence in 2020 was $16 \%$ lower than in the reference years (IRR 0.84 , CI 0.76-0.94). The monthly incidence remained near to reference levels among the youngest age group (Fig. 2A). Among children aged 1-6, the incidence was lower from April to September and again in November (Fig. 2B). A greater variation was observed among children aged 7-14 in the monthly incidence in 2020 (Fig. 2C).

\section{Discussion}

Social restrictions seemed to decrease the incidence of UTIs during the COVID-19 pandemic, especially among children aged 1-6 years. The decrease was seen in both cystitis and
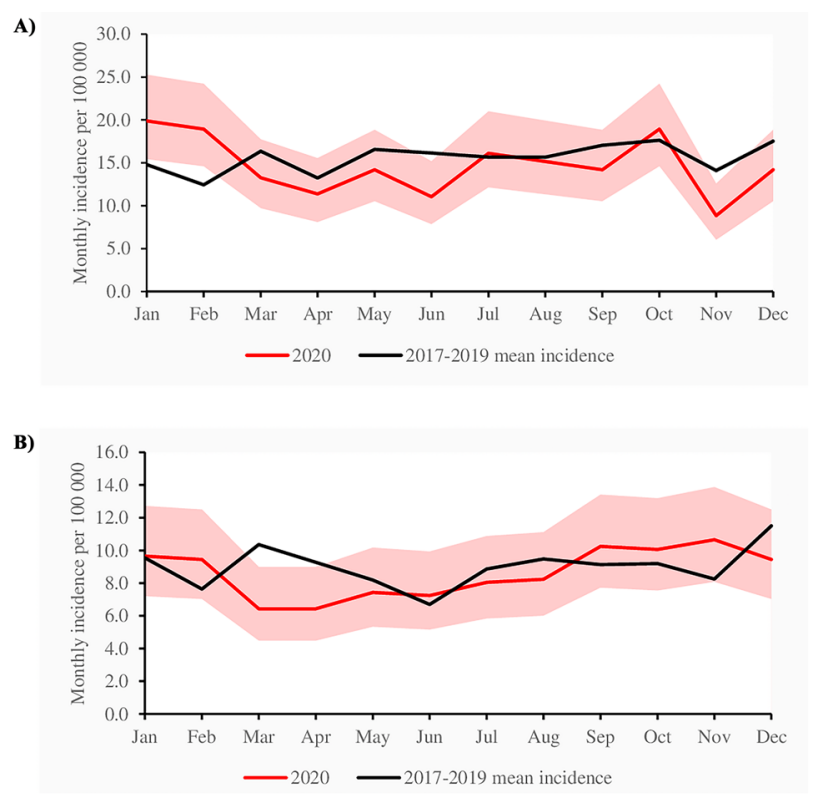

Fig. 1 A Monthly incidence of cystitis per 100,000 children aged 1-6 diagnosed treated in specialized healthcare in Finland. Light pink area indicates $95 \%$ confidence intervals. B Monthly incidence of cystitis per 100000 children aged 7-14 diagnosed and treated in specialized healthcare in Finland. Light pink area indicates 95\% confidence intervals

pyelonephritis cases. In Finland, this age group attends daycare and typically carries a heavy infectious load, especially of respiratory and gastrointestinal infections.

Our results are in line with a study from the US in which lower numbers of UTIs were detected during and right after the lockdown [5]. The studies that have reported no difference in UTI rates have been smaller and, therefore, at higher risk for being underpowered to detect changes [7, 10]. We present the first nationwide results of urinary tract
Table 1 The yearly incidence of cystitis per 100,000 children in Finland

\begin{tabular}{|c|c|c|c|c|c|c|c|c|c|c|c|}
\hline \multirow{3}{*}{ Age } & \multicolumn{4}{|c|}{ 2017-2019 } & \multicolumn{4}{|l|}{2020} & \multirow{3}{*}{ IRR } & \multirow{2}{*}{\multicolumn{2}{|c|}{$95 \mathrm{CI}$}} \\
\hline & \multirow[t]{2}{*}{$N$} & \multirow[t]{2}{*}{ Incidence } & \multicolumn{2}{|l|}{$95 \mathrm{CI}$} & \multirow[t]{2}{*}{$N$} & \multirow[t]{2}{*}{ Incidence } & \multicolumn{2}{|l|}{$95 \mathrm{CI}$} & & & \\
\hline & & & Lower & Upper & & & Lower & Upper & & Lower & Upper \\
\hline \multicolumn{12}{|c|}{ Secondary/tertiary care } \\
\hline $1-6$ years & 1911 & 187.1 & 178.9 & 195.6 & 558 & 176.1 & 162.0 & 191.2 & 0.94 & 0.86 & 1.03 \\
\hline $7-14$ years & 1598 & 108.1 & 102.8 & 113.4 & 514 & 103.3 & 94.7 & 112.9 & 0.96 & 0.87 & 1.06 \\
\hline $1-14$ years & 3509 & 140.4 & 135.8 & 145.1 & 1072 & 131.6 & 123.9 & $139-7$ & 0.94 & 0.88 & 1.00 \\
\hline \multicolumn{12}{|c|}{ Primary care } \\
\hline $1-6$ years & 2639 & 258.4 & 248.7 & 268,4 & 691 & 218.1 & 202,3 & 234.8 & 0.84 & 0.78 & 0.92 \\
\hline $7-14$ years & 2220 & 150.2 & 143.9 & 156,4 & 626 & 125.8 & 116.3 & 136.5 & 0.84 & 0.77 & 0.92 \\
\hline $1-14$ years & 4859 & 194.4 & 189.0 & 199.9 & 1317 & 161.7 & 153.2 & 170.6 & 0.83 & 0.78 & 0.88 \\
\hline \multicolumn{12}{|l|}{ Combined } \\
\hline $1-6$ years & 4550 & 445.5 & 432.7 & 458,6 & 1249 & 394.2 & 372.8 & 416.5 & 0.88 & 0.83 & 0.94 \\
\hline $7-14$ years & 3818 & 258.3 & 249.9 & 266,3 & 1140 & 229.1 & 216.1 & 243.6 & 0.89 & 0.83 & 0.95 \\
\hline $1-14$ years & 8386 & 334.8 & 327.6 & 342.0 & 2389 & 293.4 & 281.8 & 305.3 & 0.88 & 0.84 & 0.92 \\
\hline
\end{tabular}


infections during this pandemic and restriction period. Interestingly, the Italian results from a tertiary level pediatric hospital indicated that pyelonephritis cases increased during the lockdown [12]. This might have been due to patient selection as the availability of primary care resources was impacted during the major lockdown. Also, in Italy, during the first wave, the incidence of SARS-CoV-2 was high, and patients might have waited longer to seek treatment, so UTIs might have had time to evolve into pyelonephritis. Finland has had the lowest rates of COVID-19 cases in Europe, yet primary care visit rates were lower in March and April 2020 than in previous years. However, by May 2020, the visit rates had normalized and, since then, have remained above the reference level (Fig. 3). A recent report from Sweden showed similarly that the rate of UTIs increased slightly during the pandemic, although all other infections decreased [25]. This is an interesting finding as the strategy in Sweden has differed greatly from that of other European countries. The restrictions implemented in Sweden have been minimal and not as strict as here in Finland. Therefore, it could be speculated that stricter restrictions might have influenced the dynamics of UTI transmission in Finland.

UTIs have been classically considered to be noncommunicable, and the infection is thought to arise from the patient's own bacterial flora. However, our results suggest that during the social restrictions, with improved hand hygiene guidance and stay-at-home orders, the incidence of urinary tract infection was lower. This was a surprising finding. Previous findings of studies on the similar uropathogenic Escherichia coli strains in sexual partners suggest that UTIs could be transmitted during intercourse $[26,27]$. In addition to these studies, we were unable to find previous reports discussing the potential person-to-person spreading. Our results raise a question about whether the pathomechanisms and transmission dynamics of UTIs should be re-examined.

One possible explanation for our results could be that people preferred tele-health visits during the pandemic, but in Finland, the Current Care guidelines advice that UTIs in children be diagnosed and treated only after a urine sample is taken. To avoid treating of asymptomatic bacteriuria, the guidelines also instruct that urine samples
A)

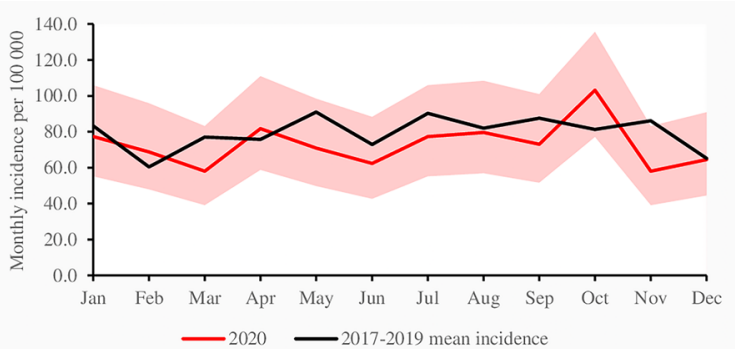

B)

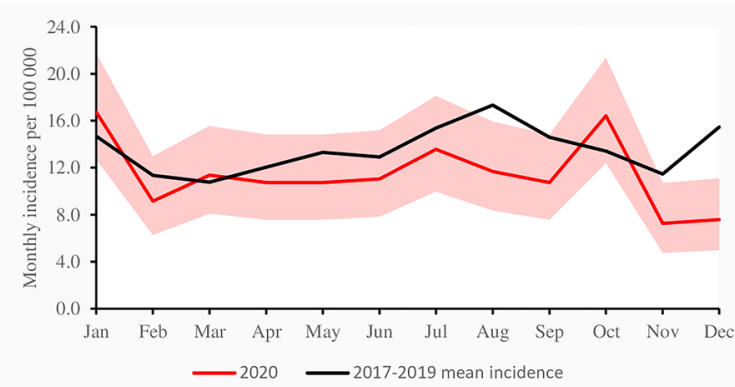

C)

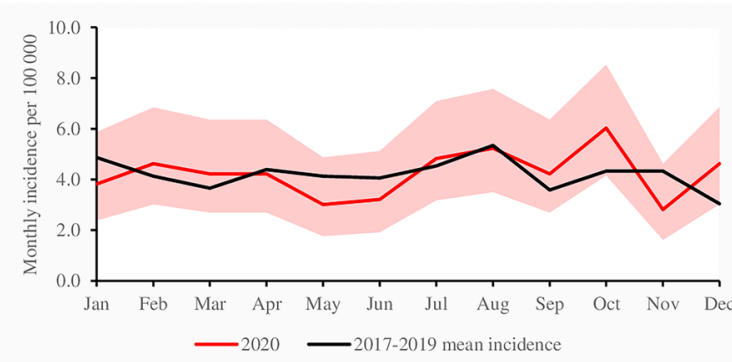

Fig. 2 A Monthly incidence of pyelonephritis per 100,000 children aged less than 1 year diagnosed and treated in specialized healthcare in Finland. Light pink area indicates 95\% confidence intervals. B Monthly incidence of pyelonephritis per 100,000 children aged 1-6 diagnosed and treated in specialized healthcare in Finland. Light pink area indicates $95 \%$ confidence intervals. C Monthly incidence of pyelonephritis per 100,000 children aged 7-14 diagnosed and treated in specialized healthcare in Finland. Light pink area indicates 95\% confidence intervals

should only be taken from children presenting symptoms suitable for UTI [24]. Due to the nature of our data, we do not know for sure if UTI diagnoses during 2020 were made in a manner similar to that in previous years. Furthermore, it might be possible that the diagnostic process
Table 2 The yearly incidence of pyelonephritis per 100,000 children in Finland in specialized healthcare

\begin{tabular}{|c|c|c|c|c|c|c|c|c|c|c|c|}
\hline \multirow{3}{*}{ Age } & \multicolumn{4}{|c|}{ 2017-2019 } & \multicolumn{4}{|l|}{2020} & \multirow{3}{*}{ IRR } & \multirow{2}{*}{\multicolumn{2}{|c|}{$95 \mathrm{CI}$}} \\
\hline & \multirow[t]{2}{*}{$N$} & \multirow[t]{2}{*}{ Incidence } & \multicolumn{2}{|l|}{$95 \mathrm{CI}$} & \multirow[t]{2}{*}{$N$} & \multirow[t]{2}{*}{ Incidence } & \multicolumn{2}{|l|}{$95 \mathrm{CI}$} & & & \\
\hline & & & Lower & Upper & & & Lower & Upper & & Lower & Uppes \\
\hline$<1$ year & 1372 & 952.8 & 903.4 & 1004.2 & 407 & 874.8 & 792.9 & 963.0 & 0.92 & 0.82 & 1.03 \\
\hline $1-6$ years & 1662 & 162.7 & 155.1 & 170.7 & 434 & 137.0 & 124.5 & 150.3 & 0.84 & 0.76 & 0.94 \\
\hline $7-14$ years & 745 & 50.4 & 46.8 & 54.1 & 253 & 50.9 & 44.9 & 57.6 & 1.01 & 0.88 & 1.16 \\
\hline $0-14$ years & 3779 & 142.9 & 138.4 & 147.6 & 1094 & 127.1 & 119.7 & 134.8 & 0.89 & 0.83 & 0.95 \\
\hline
\end{tabular}




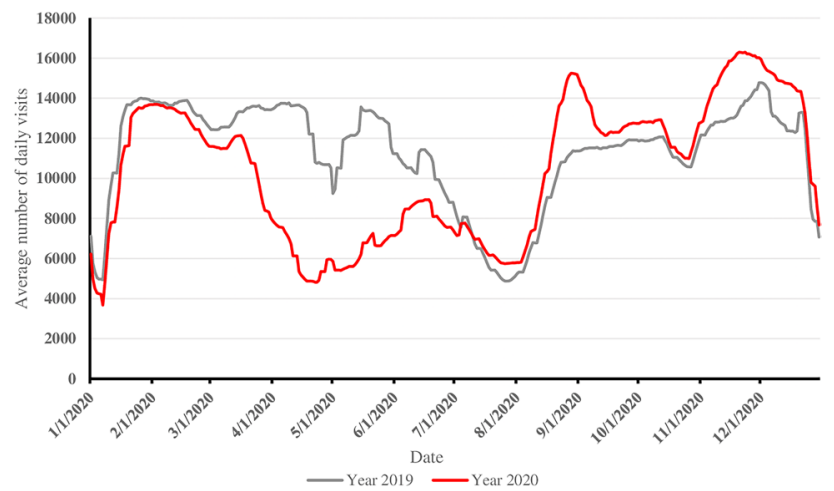

Fig. 3 Nationwide 14-day rolling mean daily visit rate for children aged 0-14 years in primary health care from 2019 to 2020 in Finland

is more specific in specialized healthcare than in primary care due to the better capacity of personnel and laboratory services. In our results, clearer decrease in cystitis incidence was observed in primary care than in secondary care, but the decrease in secondary care was borderline significant. Diagnostic accuracy of UTIs in primary care setting compared to specialized healthcare in children has not been studied in Finland.

The main strength of our study is the nationwide coverage with the register-based approach. The care register of specialized health care has a high validity, and approximately $95 \%$ of the visits are reported there [21]. The primary care register has had some problems with reporting quality, but it has improved over time and, during our study period, the reporting quality remained unchanged as over $90 \%$ of the publicly funded health care centers provided information to the register [22]. The main limitation of our study is the lack of data on hospital admissions, which could have helped to estimate the severity of diagnosed pyelonephritis cases. Further limitation is the lack of testing numbers as these are not reported to the registers. Therefore, we are unable to use test-negativity design to analyze the impact of reduced primary care resources and possible reduced urine testing numbers on the rates of UTI. However, it must be noted that as urine samples are only taken from symptomatic children, the decrease in UTI incidence would lead to lower rates of samples tested.

During the social restrictions, reduced incidences of pediatric cystitis and pyelonephritis were observed, especially in children aged 1-6 years. These results raise a question about whether the rates of urinary tract infections could be reduced by improving hygiene measures in daycare-aged children.

Supplementary Information The online version contains supplementary material available at https://doi.org/10.1007/s00431-022-04389-9.
Authors' contributions IK and MR had the original idea. MA gathered the data. MH assisted IK in statistical analysis. All the authors had access to date and have approved the statistical analysis. IK drafted the first version. All the authors participated in commenting on the manuscript and have accepted the final version to be submitted.

Funding Open access funding provided by University of Eastern Finland (UEF) including Kuopio University Hospital.

Availability of data and material Available upon request from the corresponding author.

Code availability Not applicable.

\section{Declarations}

Ethics approval Ethical approval was not required according to Finnish research laws. The ethical committees have waived ethical evaluation on all retrospective register-based studies in which the participants are not contacted.

Consent to participate According to Finnish research laws informed consent is not required when routinely collected data is handled retrospectively and the participants are not contacted.

Consent for publication According to Finnish research laws informed consent is not required when routinely collected data is handled retrospectively and the participants are not contacted.

Conflict of interest The authors declare no competing interests.

Open Access This article is licensed under a Creative Commons Attribution 4.0 International License, which permits use, sharing, adaptation, distribution and reproduction in any medium or format, as long as you give appropriate credit to the original author(s) and the source, provide a link to the Creative Commons licence, and indicate if changes were made. The images or other third party material in this article are included in the article's Creative Commons licence, unless indicated otherwise in a credit line to the material. If material is not included in the article's Creative Commons licence and your intended use is not permitted by statutory regulation or exceeds the permitted use, you will need to obtain permission directly from the copyright holder. To view a copy of this licence, visit http://creativecommons.org/licenses/by/4.0/.

\section{References}

1. Kuitunen I, Artama M, Mäkelä L, Backman K, Heiskanen-Kosma T, Renko M (2020) Effect of social distancing due to the COVID19 pandemic on the incidence of viral respiratory tract infections in children in Finland during early 2020. Pediatr Infect Dis J 39(12):e423-e427. https://doi.org/10.1097/INF.0000000000002845

2. Trenholme A, Webb R, Lawrence S et al (2021) COVID-19 and infant hospitalizations for seasonal respiratory virus infections, New Zealand, 2020. Emerg Infect Dis 27(2):641-643. https://doi. org/10.3201/eid2702.204041

3. Yeoh DK, Foley DA, Minney-Smith CA, Martin AC, Mace AO, Sikazwe CT, Le H, Levy A, Blyth CC, Moore HC (2020) The impact of COVID-19 public health measures on detections of influenza and respiratory syncytial virus in children during the 2020 Australian winter. Clin Infect Dis 28:ciaa1475. https://doi. 
org/10.1093/cid/ciaa1475. Epub ahead of print. PMID: 32986804; PMCID: PMC7543326.

4. Sullivan SG, Carlson S, Cheng AC, Chilver MB, Dwyer DE, Irwin M, Kok J, Macartney K, MacLachlan J, Minney-Smith C, Smith D, Stocks N, Taylor J, Barr IG (2020) Where has all the influenza gone? The impact of COVID-19 on the circulation of influenza and other respiratory viruses, Australia, March to September 2020. Euro Surveill 25(47):2001847. https://doi.org/10. 2807/1560-7917.ES.2020.25.47.2001847

5. Hatoun J, Correa ET, Donahue SMA, Vernacchio L (2020) Social distancing for COVID-19 and diagnoses of other infectious diseases in children. Pediatrics 146(4):e2020006460. https://doi. org/10.1542/peds.2020-006460. Epub 2020 Sep 2.

6. Gelardi M, Giancaspro R, Fiore V, Fortunato F, Cassano M (2020) COVID-19: effects of lockdown on adenotonsillar hypertrophy and related diseases in children. Int J Pediatr Otorhinolaryngol 138:110284. https://doi.org/10.1016/j.ijporl.2020.110284 (Epub 2020 Aug 9)

7. Angoulvant F, Ouldali N, Yang DD, Filser M, Gajdos V, Rybak A, Guedj R, Soussan-Banini V, Basmaci R, Lefevre-Utile A, BrunNey D, Beaujouan L, Skurnik D (2021) Coronavirus disease 2019 pandemic: impact caused by school closure and national lockdown on pediatric visits and admissions for viral and nonviral infections-a time series analysis. Clin Infect Dis 72(2):319-322. https://doi.org/10.1093/cid/ciaa710

8. Hassoun A, Pugh S, Merced I, Sharma M (2020) The power of social isolation on paediatric emergency visits during COVID-19 lockdown. Acta Paediatr 109(11):2425-2426. https://doi.org/10. 1111/apa.15490 (Epub 2020 Aug 10)

9. Iozzi L, Brambilla I, Foiadelli T, Marseglia GL, Ciprandi G (2020) Paediatric emergency department visits fell by more than $70 \%$ during the COVID-19 lockdown in Northern Italy. Acta Paediatr 109(10):2137-2138. https://doi.org/10.1111/apa.15458 (Epub 2020 Jul 22)

10. Chaiyachati BH, Agawu A, Zorc JJ, Balamuth F (2020) Trends in pediatric emergency department utilization after institution of coronavirus disease-19 mandatory social distancing. J Pediatr 20;226:274-277.e1. https://doi.org/10.1016/j.jpeds. 2020.07.048. Epub ahead of print. PMID: 32702427; PMCID: PMC7370904.

11. Ferrero F, Ossorio MF, Torres FA, Debaisi G (2021) Impact of the COVID-19 pandemic in the paediatric emergency department attendances in Argentina. Arch Dis Child 106(2):e5. https://doi. org/10.1136/archdischild-2020-319833. Epub 2020 Jun 18.

12. Liguoro I, Pilotto C, Vergine M et al (2021) The impact of COVID-19 on a tertiary care pediatric emergency department. Eur J Pediatr 180:1497-1504. https://doi.org/10.1007/ s00431-020-03909-9

13. Kruizinga MD, Peeters D, van Veen M et al (2021) The impact of lockdown on pediatric ED visits and hospital admissions during the COVID19 pandemic: a multicenter analysis and review of the literature. Eur J Pediatr. https://doi.org/10.1007/ s00431-021-04015-0

14. Haapanen M, Renko M, Artama M, Kuitunen I (2021) The impact of the lockdown and the re-opening of schools and day cares on the epidemiology of SARS-CoV-2 and other respiratory infections in children - a nationwide register study in Finland. EClinicalMedicine 34:100807. https://doi.org/10.1016/j.eclinm.2021. 100807 (Epub 2021 Mar 29)

15. Kuitunen I, Renko M (2021) Lessons to learn from the current pandemic for future non-pharmaceutical interventions against the respiratory syncytial virus - nationwide register-study in Finland. Infect Dis (Lond) 53(6):476-478. https://doi.org/10.1080/23744235. 2021.1894351 (Epub 2021 Mar 8)

16. Kuitunen I (2021) Influenza season 2020-2021 did not begin in Finland despite the looser social restrictions during the second wave of COVID-19: a nationwide register study. J Med Virol. https://doi.org/10.1002/jmv.27048. Epub ahead of print.

17. Kuitunen I, Haapanen M, Artama M, Renko M (2021) Closing Finnish schools and day care centres had a greater impact on primary care than secondary care emergency department visits. Acta Paediatr 110(3):937-938. https://doi.org/10.1111/apa.15646 (Epub 2020 Nov 11)

18. Flores-Mireles A, Walker J, Caparon M et al (2015) Urinary tract infections: epidemiology, mechanisms of infection and treatment options. Nat Rev Microbiol 13:269-284. https://doi.org/10.1038/ nrmicro3432

19. Twaij $M(2000)$ Urinary tract infection in children: a review of its pathogenesis and risk factors. J R Soc Promot Health 120(4):220 226. https://doi.org/10.1177/146642400012000408

20. Robino L, Scavone P, Araujo L, Algorta G, Zunino P, Pírez MC, Vignoli R (2014) Intracellular bacteria in the pathogenesis of Escherichia coli urinary tract infection in children. Clin Infect Dis 59(11):e158-e164. https://doi.org/10.1093/cid/ciu634 (Epub 2014 Aug 4)

21. Care Register. Finnish Institute of Health and Welfare. Accessed 10 Jun 2021. https://thl.fi/en/web/thlfi-en/statistics/informationon-statistics/register-descriptions/care-register-for-health-care

22. Primary Health Care Register. Finnish Institute of Health and Welfare. Accessed 10 Jun 2021. https://thl.fi/en/web/thlfi-en/statistics/ information-on-statistics/quality-descriptions/primary-health-care

23. Finnish inhabitants, Population information system. Statistics Finland. Open Access population statistics. Available from: https:// stat.fi/index_en.html. Cited 31 Aug 2021

24. Urinary tract infections (2019) Current care guidelines. Working group set by the Finnish Society of Infectious Diseases, Finnish Society of Clinical Chemistry, Finnish Paediatric Society, Finnish Urology Association and The Finnish Association of General Practitioners. Helsinki: The Finnish Medical Society Duodecim. Accessed 10 Jun 2021. Available online: www.kaypahoito.fi (In Finnish).

25. Rhedin SA, Ryd Rinder M, Hildenwall H, Herlenius E, Hertting O, Luthander J, Melén E, Nijman R, Olsson-Åkefeldt S, Alfven T (2021) Reduction of pediatric emergency visits during the COVID19 pandemic in a region with open preschools and schools. Acta Paediatr. https://doi.org/10.1111/apa.15978

26. Foxman B, Zhang L, Tallman P, Andree BC, Geiger AM, Koopman JS, Gillespie BW, Palin KA, Sobel JD, Rode CK, Bloch CA, Marrs CF (1997) Transmission of uropathogens between sex partners. J Infect Dis 175(4):989-992. https://doi.org/10.1086/514007

27. Ulleryd P, Sandberg T, Scheutz F, Clabots C, Johnston BD, Thuras P, Johnson JR (2015) Colonization with Escherichia coli strains among female sex partners of men with febrile urinary tract infection. J Clin Microbiol 53(6):1947-1950. https://doi.org/10.1128/ JCM.00579-15

Publisher's Note Springer Nature remains neutral with regard to jurisdictional claims in published maps and institutional affiliations. 